\title{
Successful surgical treatment of hypoplastic left heart syndrome associated with a divided left atrium that was diagnosed intraoperatively
}

\author{
Yuji Naito, MD, ${ }^{\text {a }}$ Yorikazu Harada, MD, ${ }^{\text {a }}$ Shunji Uchita, MD, ${ }^{\text {a }}$ Koki Takizawa, MD, ${ }^{\text {a }}$ Gengi Satomi, MD,
} Satoshi Yasukochi, MD, ${ }^{\mathrm{b}}$ and Hikoro Matsui, MD, ${ }^{\mathrm{b}}$ Nagano, Japan

$\mathrm{H}$ ypoplastic left heart syndrome (HLHS) often involves abnormalities in atrial septal morphology, including a restrictive atrial communication and anomalous attachment of a malaligned septum primum. Cor triatriatum is a rare congenital heart abnormality in which the left atrium (LA) is divided into 2 chambers by a diaphragm. Association of cor triatriatum with HLHS is rare, and cor triatriatum is difficult to diagnose preoperatively. We herein describe an unusual case of HLHS with cor triatriatum.

\section{Clinical Summary}

The patient was a neonate (7-day-old boy, $2.46 \mathrm{~kg}$ ) in whom HLHS was diagnosed prenatally. Delivery was uncomplicated at 37 weeks' gestation. Intravenous infusion of prostaglandin was initiated to maintain the systemic circulation through the patent ductus arteriosus. Chest radiography showed an enlarged cardiac shadow with a cardiothoracic ratio of $58 \%$ and lung congestion with signs of severe pulmonary venous congestion. Echocardiography revealed anatomy consistent with HLHS: restrictive patent foramen ovale (PFO), patent ductus arteriosus, persistent left superior vena cava (SVC), severe mitral valve stenosis, and severe aortic valve stenosis. The progressive pulmonary congestion was presumed to be due to the restrictive PFO, and first-stage palliation was indicated.

The patient underwent Norwood repair at 8 days of age. An abnormal pulmonary venous connection was anticipated from the unidentified anatomic structure found at the superior surface of the LA. After initiation of cardiopulmonary bypass, hypothermic cardioplegic arrest was induced. The right atrium (RA) was cut open to confirm that the fossa ovalis was intact, with no interatrial communication. The fossa ovalis was cut open to create an unrestricted interatrial communication. After morphologic examination, another unidentified orifice located superior to the fossa ovalis was confirmed, and it was determined that this orifice was

From the Departments of Cardiovascular Surgery ${ }^{\mathrm{a}}$ and Cardiology, ${ }^{\mathrm{b}} \mathrm{Na}-$ gano Children's Hospital, Nagano, Japan.

Received for publication Aug 26, 2006; accepted for publication Sept 5, 2006.

Address for reprints: Yuji Naito, MD, Department of Cardiovascular Surgery, Nagano Children's Hospital, 3100, Toyoshina, Azumino-shi, Nagano, 399-8205, Japan (E-mail: ujinaito@aol.com).

J Thorac Cardiovasc Surg 2007;133:813-5

$0022-5223 / \$ 32.00$

Copyright $\odot 2007$ by The American Association for Thoracic Surgery

doi:10.1016/j.jtcvs.2006.09.064 a connection between the common pulmonary vein chamber (CPVC) and the RA (Figures 1 and 2, A). The orifice was enlarged to relieve the pulmonary venous congestion, and the endocardium was approximated to prevent future obstruction and atrial thrombus formation. The patient was weaned uneventfully from cardiopulmonary bypass and recovered well after delayed sternal closure.

Magnetic resonance imaging (MRI) after the first-stage palliative operation revealed a divided LA with a muscular diaphragm completely separating the CPVC and the LA. It was presumed that the preoperatively diagnosed unidentified orifice on the atrial septum, which was enlarged during the first operation, was the communication between the RA and the CPVC. The patient gradually showed symptoms of pulmonary venous obstruction, and echocardiography showed accelerated left-toright shunt flow across the surgically enlarged interatrial communication.

Second-stage palliative surgery consisting of a bidirectional Glenn anastomosis and creation of unrestricted communication between the CPVC and RA was successfully performed when the patient was 5 months old and weighed $3.8 \mathrm{~kg}$ (Figure 2B). After establishment of cardioplegic arrest, the RA was reopened. Through the surgically created PFO, the atretic mitral valve and left atrial appendage were confirmed, but the aperture on the diaphragm was not identified. Both the atrial septum and the diaphragm were widely excised to create sufficient communication from the CPVC to the RA. After resection of the diaphragm, the unobstructed orifices of all pulmonary veins were found in the CPVC. The right SVC alone was anastomosed to the right pulmonary artery by using continuous sutures because angiographic examination after first-stage palliation had confirmed that the left SVC was occluded.

The postoperative course was uneventful, MRI depicted an unrestricted pulmonary venous pathway, and echocardiography showed no acceleration of the pulmonary venous drainage.

\section{Discussion}

Association of cardiac anomalies with HLHS is uncommon. Such anomalies reportedly include intact atrial septum, total anomalous pulmonary venous connection (TAPVC), levoatrial cardinal vein, coronary sinus atresia, atretic pulmonary veins, complete atrioventricular septal defect, and transposition of the great arteries. ${ }^{1}$ Eidem and Cetta $^{2}$ first described the rare association between cor triatriatum, which is not a well-recognized morphologic defect, and $\mathrm{HLHS}^{2}$ Cor triatriatum is a rare congenital cardiac anomaly in which the pulmonary veins enter a posterosuperior proximal left atrial chamber that is separated from the anteroinferior 


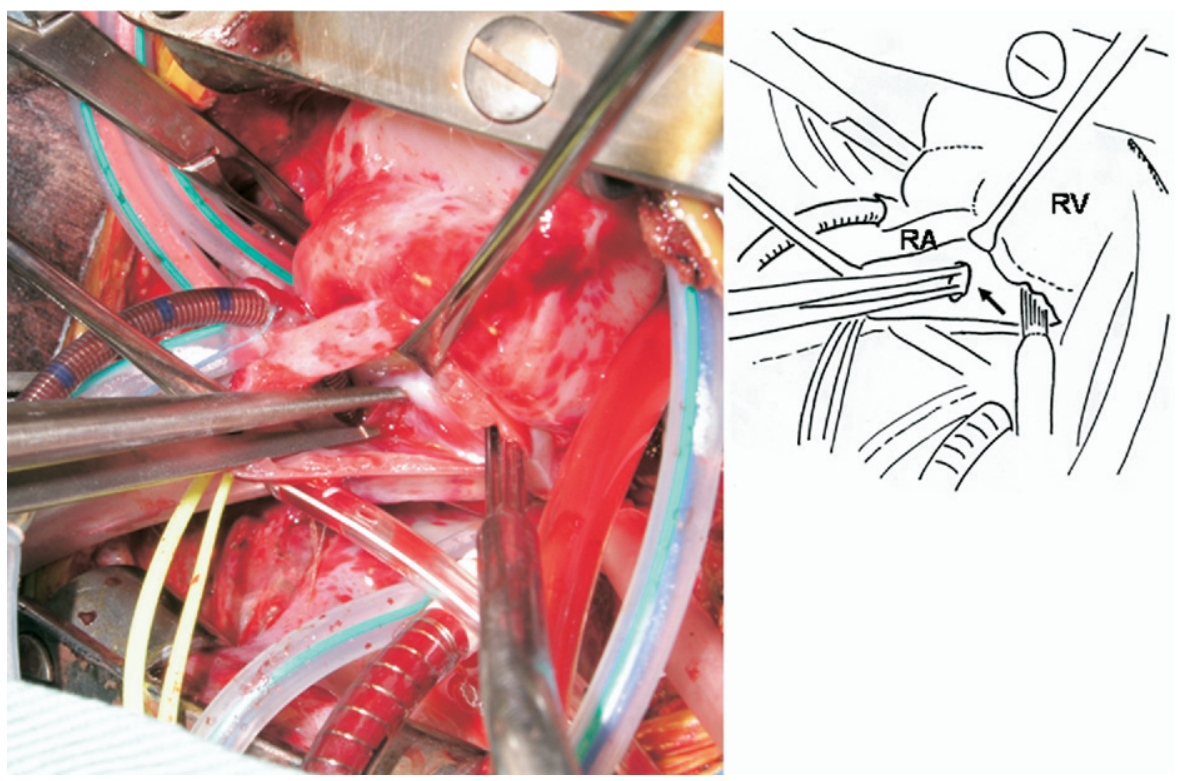

Figure 1. Photograph obtained during the first-stage palliative operation. The arrow indicates the orifice of the communication between the common pulmonary vein chamber (CPVC) and the right atrium $(R A)$. $R V$, Right ventricle.

distal left atrial chamber bearing the mitral valve and left atrial appendage by a diaphragm in which there are 1 or more restrictive ostia.

In the present case the clinical diagnosis presented some morphologic puzzles. The connection between the CPVC and RA could have been diagnosed as either TAPVC or cor triatriatum. In cases of cor triatriatum, each pulmonary vein can be considered as not joining the LA but rather as entering a separate chamber, called the CPVC or proximal left atrial chamber, which is analogous to the common pulmonary venous sinus found in patients with TAPVC. In this respect cor triatriatum is similar to TAPVC, but the pulmonary veins in cor triatriatum are incorporated into the structure of the LA, whereas in TAPVC the pulmonary veins connect to sites separate from the LA. ${ }^{3}$ Because the diaphragm between the LA and CPVC was confirmed and resected in our patient's second palliative operation and all pulmonary veins entered a single chamber thought to be part of the LA, we concluded that the atrial morphology was that of cor triatriatum with a morphologic classification of IB1 according to the Lucas-Schmidt system or subtype A2 according to Lam's classification system.

The prospective detection rate of pulmonary venous abnormalities by means of MRI is reported to be superior to that by means of echocardiography. ${ }^{4}$ If pulmonary venous abnormality is suspected and the neonate's hemodynamic condition is stable, MRI can provide useful information.
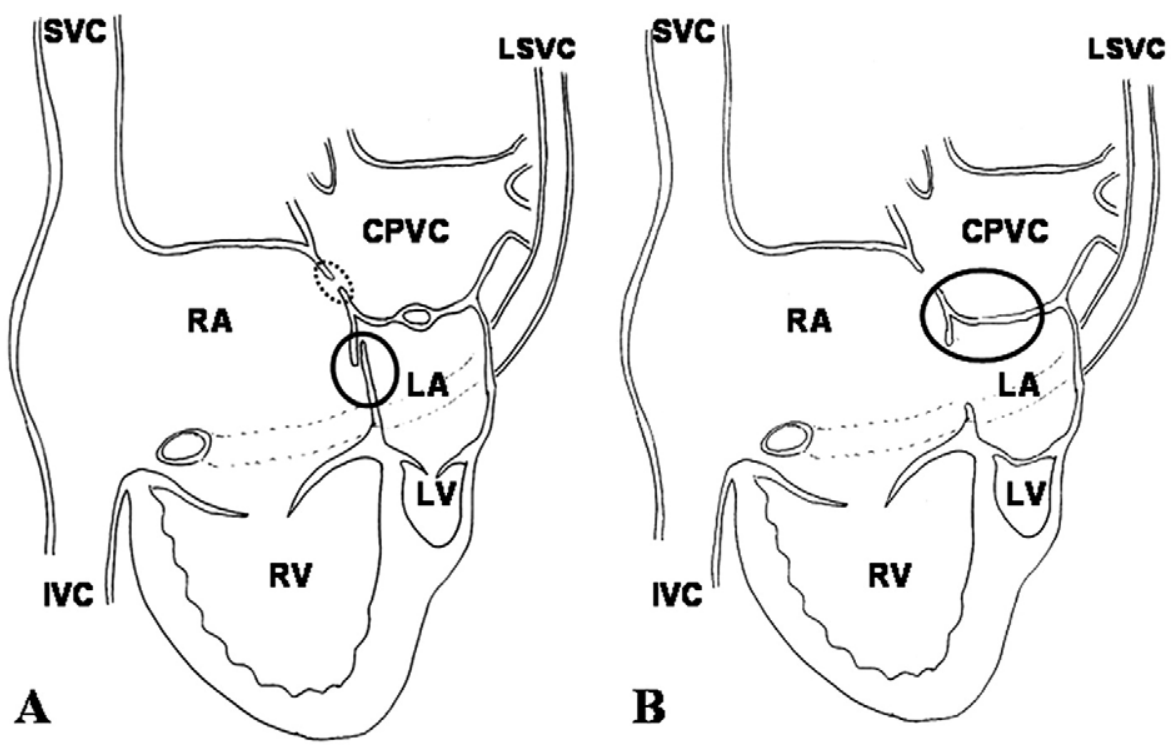

Figure 2. Schemas of atrial and ventricular morphology in the first-stage $(A)$ and second-stage (B) palliative operations. A, The intact fossa ovalis (solid circle) was cut open to create an unrestricted interatrial communication. The stenotic communication between the CPVC and RA (dashed circle) was enlarged to relieve the pulmonary venous congestion. $B$, Both the atrial septum and the diaphragm (solid circle) were widely excised to create sufficient communication from the common pulmonary vein chamber to the right atrium. CPVC, Common pulmonary venous chamber; $I V C$, inferior vena cava; $L A$, left atrium; $L S V C$, left superior vena cava; $\boldsymbol{L} V$, left ventricle; $R A$, right atrium; $R V$, right ventricle; $S V C$, superior vena cava. 


\section{References}

1. Kouchoukos NT, Blackstone EH, Doty DB, et al. Aortic atresia and other forms of hypoplastic left heart physiology. Cardiac Surgery, Vol. 2. New York, NY; Churchill Livingstone; 2003. p. 1377-400.

2. Eidem BW, Cetta F. Unusual finding of cor triatriatum in a newborn with hypoplastic left heart syndrome. J Am Soc Echocardiogr. 2001;14:850-2.
3. Kouchoukos NT, Blackstone EH, Doty DB, et al. Cor triatriatum. Cardiac surgery, Vol. 2. New York, NY; Churchill Livingstone; 2003. p. 781-9.

4. Masui T, Seelos KC, Kersting-Sommerhoff BA, Higgins CB. Abnormalities of the pulmonary veins: evaluation with MR imaging and comparison with cardiac angiography and echocardiography. Radiology. 1991;181:645-9.

\title{
Improved lung perfusion with surgical correction of pulmonary artery sling
}

\author{
Emmanuel Le Bret, MD, PhD, ${ }^{a}$ Brigitte Fauroux, MD, PhD, ${ }^{\mathrm{c}, \mathrm{f}}$ Anne Sigal-Cinqualbre, MD, ${ }^{\mathrm{b}}$ \\ Claire de Labriolle-Vaylet, MD, PhD, ${ }^{\mathrm{d}}$ Alain Batisse, $\mathrm{MD},{ }^{\mathrm{e}}$ Régine Roussin, $\mathrm{MD}$, \\ Emre Belli, MD, and Alain Serraf, MD, PhD, ${ }^{a}$ Le Plessis Robinson and Paris, France
}

I n pulmonary arterial sling (PAS), the left pulmonary artery (LPA) arises from the right pulmonary artery (RPA) and goes leftward between the trachea and the esophagus. This produces a sling around the distal trachea and the proximal bronchi. The LPA thus compresses the superior part of the right bronchus and the distal part of the trachea. Most patients with PAS have clinical symptoms related to tracheal or tracheobronchial compression. When tracheal hypoplasia coexists (ring-sling complex ${ }^{1}$ ), acute episodes of dyspnea and cyanosis are common and may cause major respiratory distress and death. Although the effect of PAS on lung ventilation is well known, the effect of the surgical correction of PAS on left lung perfusion has never been evaluated.

\section{Clinical Summary}

A 5-year-old boy with a history of recurrent pulmonary infections was referred to the pediatric pneumology department.

Preoperative examination. On examination, the patient was an alert and vigorous child weighing $18 \mathrm{~kg}$. Results of clinical examination at rest were normal. A chest radiograph revealed that the left lung was smaller than the right lung, with a minimal shift of the heart and mediastinal structures to the left. Bronchoscopy revealed a mild

From the Département des Cardiopathies Congénitales ${ }^{\mathrm{a}}$ and the Département d'Imagerie Médicale, ${ }^{\text {b }}$ Centre Chirurgical Marie Lannelongue, Université Paris XI, Le Plessis Robinson, France, and the Service de Pneumologie Pédiatrique ${ }^{\mathrm{c}}$ and the Service de Médecine Nucléaire Pédiatrique, ${ }^{\mathrm{d}}$ Hôpital d'Enfants Armand Trousseau, Université Paris VI, Paris, France, and the Unité d'Explorations Cardiologiques, Institut de Puériculture de Paris, ${ }^{\mathrm{e}}$ Paris, France; INSERM UMR-S U 719, ${ }^{\mathrm{f}}$ Paris, France.

Received for publication Sept 6, 2006; accepted for publication Oct 23, 2006.

Address for reprints: Emmanuel Le Bret, $\mathrm{MD}, \mathrm{PhD}$, Département des Cardiopathies Congénitales, Centre Chirurgical Marie Lannelongue, 133 Avenue de la Résistance, 92350 Le Plessis Robinson, France (E-mail: e.lebret@ccml.fr).

J Thorac Cardiovasc Surg 2007;133:815-6

$0022-5223 / \$ 32.00$

Copyright $\odot 2007$ by The American Association for Thoracic Surgery doi:10.1016/j.jtcvs.2006.10.031 compression of the distal trachea by as much as a third of its lumen. A 2-dimensional echocardiogram showed a PAS with a small LPA (7-8 mm) and a large RPA (13-14 mm). A multislice computed tomographic scan confirmed the presence of the PAS and showed the smaller LPA stretched around the trachea (Figure 1).

Ventilation scintigraphy with xenon 133 revealed a mild ventilation asymmetry (55\% for the right lung and $45 \%$ for the left lung), whereas perfusion scintigraphy with albumin, aggregated technetium macro aggregated albumin labeled with Technetium99m (Tc 99m MAA) revealed severe hypoperfusion of the left lung, with a right to left perfusion ratio of $90 \%$ to $10 \%$ (Figure 2, A).

Surgical correction of the vascular malformation was elected to preserve both the perfusion and the function of the left lung.

Operative technique. The operation was performed through a median sternotomy under normothermic cardiopulmonary bypass. The ligamentum arteriosum was divided. The LPA was detached from the RPA, dissected free where it coursed behind the trachea, and translocated to the left side of the trachea. It was then shortened to be implanted to the left side of the main pulmonary artery where the ligamentum arteriosus was inserted. The operative sizing of the pulmonary arteries revealed a mildly hypoplastic LPA relative to the RPA. The anastomosis was performed with continuous 6.0 absorbable monofilament sutures.

Postoperative status. The child was extubated in the operating room. He remained less than 24 hours in the intensive care unit and was discharged from the hospital on the sixth day.

Follow-up. At 5 months, the child was perfectly well, with strictly normal results of clinical examination. According to chest radiography, the left lung remained a little bit smaller than the right one. The perfusion scan showed an increase in the left lung perfusion, with a right to left ratio of $71 \%$ to $29 \%$. At 1 year, the echocardiographic estimate of the LPA diameter remained similar to the preoperative value, but the perfusion scan showed an improvement of the right to left perfusion ratio at $65 \%$ to $35 \%$ (Figure 2, B).

\section{Discussion}

In PAS, left lung perfusion can be dramatically decreased. First, the LPA is usually smaller than the RPA. ${ }^{2}$ Second, the course of 